\title{
A MUSICALIZAÇAO, O LUDICO E A AFETIVIDADE NA EDUCAÇÃO INFANTIL
}

Maria Eliza de Oliveira ${ }^{1}$, Sueli Felicio Fernandes ${ }^{1}$, Luciana Carolina Fernandes de Faria ${ }^{2}$

${ }^{1}$ Discente do curso de Música-Licenciatura da Universidade do Oeste Paulista - UNOESTE. ${ }^{2}$ Mestranda em Educação pela UNOESTE, docente do curso de Música-Licenciatura da Universidade do Oeste Paulista - UNOESTE.

\section{RESUMO}

Este artigo tem por objetivo refletir a importância da Educação Musical e identificar quais suas contribuições para o ensino, quando integrada à afetividade e ao lúdico na Educação Infantil. Além de ser conteúdo específico e essencial para a formação integral do ser humano, a música promove melhora significativa no processo de aprendizagem da criança, quando aplicada de forma integrada a métodos lúdicos. A música articulada com o lúdico torna as atividades mais prazerosas, aproximando educador e educando e potencializando a afetividade no contexto de sala de aula, promovendo, assim, o desenvolvimento social, afetivo e cognitivo do aluno. Tal afetividade é essencial para a Educação Infantil, e faz com que a tarefa de aprender seja mais agradável e envolvente para o aluno.

Palavras-chave: Educação Infantil, Educação Musical, Afetividade, Lúdico.

\section{INTRODUÇÃO E OBJETIVOS}

A educação infantil é a primeira etapa da educação básica, tendo a responsabilidade de educar e preparar a criança para o ensino fundamental,visando seu desenvolvimento integral.Segundo a LDB 9.394/96, "a educação infantil no Brasil compreende o atendimento às crianças com idade entre 0 e 6 anos de idade. As crianças de 0 a 3 anos de idade são atendidas pelas creches, e as crianças entre 4 e 6 anos pelas pré-escolas." (BRASIL, 1996, p. 26).

O papel da educação infantil é cuidar da criança fornecendo alimentação, cuidando da sua higiene, tendo, assim, um caráter assistencialista, proporcionando também lazer e educação. Esta educação tem caráter lúdico, visando o desenvolvimento integral da criança, mas sem objetivo específico de alfabetização. Os professores e agentes da Educação Infantil buscam desenvolver atividades que estimulem a sociabilidade com outras crianças e adultos, ensinar as crianças a se expressarem através da linguagem, estimular a curiosidade a fim de ampliar seus conhecimentos e ações, dentro de um ambiente que faça a criança se sentir segura e feliz. Para tanto o educador assume um papel mediador entre a criança e o objeto do conhecimento:

“... o professor entra como mediador entre a criança e o objeto do conhecimento, propiciando espaços e situações de aprendizagens que envolvam todas as capacidades como, afetivas, cognitivas, emocionais, sociais, etc., explorando os diferentes campos de conhecimentos humanos. O professor tem a função de propiciar à criança, uma ambiente saudável, 
sem descriminação, rico, prazeroso, onde é possível explorar as variadas práticas educativas e sociais" (UBALDO, 2009).

Um dos aspectos que fazem com que a criança se sinta bem no espaço escolar é o vínculo afetivo, não só do professor, mas de todos com quem mantém contato dentro da instituição de ensino.Wallon (1975), defineo termo afetividade como sendo a capacidade do ser humano de ser afetado positiva ou negativamente tanto por sensações internas como externas. A afetividade é um dos conjuntos funcionais da pessoa e atua juntamente com a cognição e o ato motor, no processo de desenvolvimento e construção do conhecimento.

Na concepção de Piaget (1996), afetividade é o agente motivador da atividade cognitiva. A afetividade e a razão são termos complementares e seria aenergia, o que move a ação, enquanto a razão seria o que possibilita ao sujeito identificar desejos, sentimentos variados, e obter êxito em suas ações. O processo afetivo é continuo e inovador, e está sempre em construção. A formação de sentimentos está ligada a valores e evolução da sociedade, e os sentimentos são constituídos a partir da cooperação de outros, a partir do convívio.

Segundo Rossini (2003), por meio da afetividade a aprendizagem se torna mais viável, os relacionamentos se tornam mais felizes e saudáveis, e a interação e a integração da criança com o mundo torna-se mais espontânea e emotiva.

As crianças devem ter oportunidade de desenvolver sua afetividade. É preciso dar-lhes condições para que seu emocional floresça, se expanda, ganhe espaço. A falta de afetividade leva a rejeição aos livros, à carência de motivação para aprendizagem, à ausência de vontade de crescer. (Rossini, 2001, p. 15 e 16).

Assim, a aprendizagem deve estar ligada ao ato afetivo, deve ser prazerosa.

A afetividade é a base da vida e elemento importante no processo de aprendizagem. Piaget afirma que a afetividade não modifica a estrutura no funcionamento da inteligência, porém, é a energia que impulsiona a ação de aprender. Poderá acelerar ou retardar o desenvolvimento dos indivíduos, podendo até interferir no funcionamento das estruturas da inteligência. (Andrade, 2007)

Wallon (1975), afirma que tanto os laços de afetividade quanto a aprendizagem tem início no âmbito familiar e se estende posteriormente à escola, e a criança irá conviver nestes dois meios durante a principal fase de sua vida, fase esta, em que sua personalidade está em formação. Nesta fase muitos conflitos podem ser gerados, e o professor pode fazer a diferença. 
Para Almeida (2005), se o professor tiver conhecimento do conflito eu-outro na construção da personalidade do aluno, com certeza, ele saberá conduzir as relações e receberá esses estímulos com mais calma, não tomando os mesmos como uma questão pessoal.O professor precisa não só compreender o aluno e seu universo sociocultural, mas estar consciente de que educar é um ato que exige uma pré-disposição de amar. Hoje muito se sabe que a cognição e a emoção são fatores inseparáveis do ser humano, e para que ocorra desenvolvimento não apenas intelectual, mas integral do educando, que é o objetivo da educação infantil, é muito importante que a educação estimule o desenvolvimento da sensibilidade e da expressão da emoção, que pode ser desenvolvido por meio da linguagem artística e da música, e utilize-se de recursos lúdicos que envolvem e aproximam os alunos.

Lúdico é todo e qualquer movimento que tem como objetivo produzir prazer na sua execução, ou seja, divertir o praticante. As características dos jogos lúdicos são: brinquedos ou brincadeiras menos consistentes e mais livres de regras e normas; são atividades que não visam a competição como objetivo principal, mas a realização de uma tarefa de forma prazerosa; existe sempre a presença de motivação para atingir os objetivos. (REZENDE, 1993)

Sob o ponto de vista de Vygotsky (1991, p. 97), asatividades lúdicas são fontes de desenvolvimento proximal, pois a criança quando brinca demonstra e assume um comportamento mais desenvolvido do que aquele que tem na vida real, envolvendo-se por inteiro na brincadeira. Estas oportunizam situações de atuação coletiva, possibilitam imitações de comportamentos mais avançados de outro semelhante, a prática de exercício de funções e papéis para os quais ela ainda não está apta; o conhecimento e o contato com objetos reais e com aqueles criados para atender aos seus desejos de experimentação. O professor pode desenvolver, por meio da brincadeira, conhecimentos, habilidades e comportamentos que estão latentes ou em estado de formação na criança.

Para Pinho (2009), as brincadeiras e jogos podem e devem ser utilizados como ferramenta importante de educação. Na educação infantil, as atividades lúdicas são mais empregadas no aprendizado das crianças de 0 a 5 anos de idade, onde elas interagem umas com as outras, desempenhando papeis sociais, desenvolvendo a imaginação, criatividade e capacidade motora e de raciocínio. Alguns educadores julgam necessário que as brincadeiras sejam direcionadas e possuam um objetivo claro, sob o argumento de que são importantes no desenvolvimento integral da criança. 
De acordo com Ana Mae Barbosa (2011, p. 18), "a Arte como uma linguagem aguçadora dos sentidos transmite significados que não podem ser transmitidos por intermédio de nenhum outro tipo de linguagem, tais como a discursiva e científica". Nesse sentido a música é um meio de expressão e forma de conhecimento, sendo um meio para o desenvolvimento da expressão, do equilíbrio, da autoestima e autoconhecimento, além de um meio de integração social.

Este artigo tem como objetivo mostrar a importância da educação musical e quais as contribuições da música quando integrada com a afetividade e o lúdico na educação infantil.

\section{METODOLOGIA}

Considerando o propósito deste artigo, o procedimento metodológico utilizado foi a pesquisa bibliográfica e documental, tendo como base o trabalho de identificar, analisar e interpretar a Lei de Diretrizes e Bases da Educação e os documentos de orientação propostos pelo MEC, como os Referenciais Curriculares Nacionais para a Educação Infantil, bem como autores que discutem a Educação Musical no contexto escolar, a fim de compreender como a música, quando integrada à afetividade e ao lúdico, contribui para a formação da criança.

\section{RESULTADOS}

A lei 11.769/08 altera a lei 9.394/96, Lei de Diretrizes e Bases da Educação, para dispor sobre a obrigatoriedade do ensino da música na Educação Básica. Assim, a própria Lei e o Referencial Curricular Nacional da Educação Infantil justificam a finalidade da música nas escolas, e firma sua importância na educação. O Referencial Curricular Nacional para a Educação Infantil cita a importância da música na Educação:

Pesquisadores e estudiosos vêm traçando paralelos entre o desenvolvimento infantil e o exercício da expressão musical, resultando em propostas que respeitam o modo de perceber, sentir e pensar, em cada fase, e contribuindo para que a construção do conhecimento dessa linguagem ocorra de modo significativo. O trabalho com Música proposto por este documento fundamenta-se nesses estudos, de modo a garantir à criança a possibilidade de vivenciar e refletir sobre questões musicais, num exercício sensível e expressivo que também oferece condições para o desenvolvimento de habilidades, de formulação de hipóteses e deelaboração de conceitos(BRASIL, 1998, pg. 48).

Cada sociedade tem uma maneira de compreender as formas de expressões artísticas e valorizá-las. Valorização esta, que a música e a educação musical ainda não conseguiram alcançar plenamente nas escolas brasileiras. 
A música, além de possibilitar comunicar sentimentos que não são possíveis de expressar apenas com a fala, pode auxiliar no desenvolvimento humano, aprimorando a sensibilidades, a concentração e a memória. A música, além de conteúdo específico, pode contribuir no processo de alfabetização e raciocínio lógico.

Merriam(apud Swanwick, 2003, p. 47) classificou e categorizou a música em dez funções para a sociedade, e cada uma usa a música de sua maneira particular.

Merriam lembra-nos a variedade de propósitos para as quais a música é "boa para". Em sua própria ordem, eles são os seguintes: expressão emocional; prazer estético; diversão; comunicação; representação simbólica; resposta física; reforço da conformidade a normas sociais; validação de instituições sociais e rituais religiosos; contribuição para continuidade e estabilidade da cultura e a preservação da integração social. (SWANWICK, p. 47)

Não devemos, nem podemos aprisionar a música em bancos escolares duros e imóveis. Música é movimento, aventura, criação, sensação, devir, e desse modo, considero, deve estar presente nos planos da educação. Respeitando tempos e lugares, alunos e comunidades, buscando singularizar as experiências que emergem em distintos contextos, sem as amarras dos modelos e dos sistemas estritos que, não raro, tendem a aprisionar o fato musical em algumas de suas regras. É necessário instaurar campos de criação, de experimento, de potencialização de escutas criativas, críticas e transformadoras, abertas às "muitas músicas da música", às paisagens sonoras, aos planos da improvisação, do cantar e dançar, da pesquisa, da produção de materiais sonoros e muito mais. (BRITO, 2010, 92)

\section{DISCUSSÃO}

Como citado anteriormente, a música ajuda no desenvolvimento da expressão emocional, na capacidade de concentração e memorização, auxiliando no processo de alfabetização, e ainda estimulando áreas do cérebro não desenvolvidas por outras linguagens, sendo que quando bem aplicada, contribui para enriquecer o conhecimento, sempre respeitando o modo de perceber, sentir e pensar em cada fase de desenvolvimento da criança.

Bréscia (2003) cita a musicalização como sendo um processo de construção do conhecimento, que tem como objetivo despertar e desenvolver o gosto musical, favorecendo o desenvolvimento da sensibilidade, criatividade, senso rítmico, do prazer de ouvir música, da imaginação, memória, concentração, atenção, autodisciplina, do respeito ao próximo, da socialização e afetividade, também contribuindo para uma efetiva consciência corporal e de movimentação. 
Segundo Fonterrada (2008), a educação infantil, a musicalização, a afetividade, e as atividades lúdicas se integram, pois têm como objetivo o desenvolvimento sócio-afetivo e cognitivo da criança. A autora usa os termos: educar, aprender, cuidar e brincar.

Para poder efetivar as práticas desses pressupostos, é necessário não somente as Leis, que regulamentam a educação infantil e o ensino de música, como também de professores capacitados; estabelecer metas; objetivos; planos e conteúdos. Sabe-se que, as escolas e creches, em sua maioria não têm estrutura física e materiais para concretização do ensino de música, mas com capacitação, criatividade e empenho os educadores podem oferecer aulas de música de qualidade aos alunos.

Para Brito (2010), o conteúdo a ser aplicado deve ser vinculado às características socioculturais da comunidade a qual pertence a escola ou creche, de modo atender às necessidades e expectativas. Quanto mais próxima estiver a realidade da comunidade e a escolha desse conteúdo, maior a possibilidade de criar um ambiente positivo e de forte conotação afetiva.

Marisa Fonterrada (2008), em seu livro Tramas e Fios, sugere que as atividades lúdicas podem ajudar nas aulas de música, uma vez que nem sempre é necessário ou possível ter instrumentos musicais para todas as crianças. Há outras formas de efetivar a musicalização que dispensam instrumentos musicais, e podem ser muito proveitosas, explorando métodos de educadores como Carl Orff, Dalcroze e Schafer, que nos possibilita fazer uso do lúdico na prática da educação musical, dando ênfase não apenas ao desenvolvimento cognitivo, mas também ao psicomotor, sensível e social, explorando ao máximo o estímulo da afetividade entre os alunos, e entre alunos e professor. Desta forma, a música pode contribuir para um ambiente de sala de aula mais acolhedor e descontraído, e com isto, possibilitar ações de alunos mais dispostos à receptividade de outras disciplinas.

As crianças gostam de acompanhar as músicas com movimentos do corpo, tais como palmas, sapateados, danças volteios de cabeça, mas, inicialmente, é esse movimento bilateral que ela irá realizar. E é a partir dessa relação entre o gesto e o som que a criança - ouvindo, cantando, imitando, dançando - constrói seu conhecimento sobre a música, percorrendo o mesmo caminho do homem primitivo na exploração e na descoberta dos sons. (JEANDOT, 1990, p. 19).

\section{CONCLUSÃO}

Contando com todos os benefícios que a educação musical traz podemos explorar métodos que nos permita fazer uso do lúdico na prática, dando ênfase não apenas ao desenvolvimento cognitivo, psicomotor, e outros pontos positivos, e explorar ao máximo o estímulo da afetividade 
entre os alunos, e entre alunos e professor, fazendo com que o ambiente de sua sala de aula se torne aconchegante e descontraído, e com isto, teremos alunos mais dispostos à receptividade de outras disciplinas.

A integração entre os aspectos sensíveis, afetivos, estéticos e cognitivos, assim como a promoção de interação e comunicação social, conferem caráter significativo à linguagem musical. É uma das formas importantes de expressão humana, o que por si só justifica sua presença no contexto da educação, de um modo geral, e na educação infantil, particularmente. (BRASIL, 1998, p.45).

Na educação infantil a escola e o professor devem trabalhar juntos para propiciar espaços e situações de aprendizagens que envolvam todas as capacidades humanas, como, afetivas, cognitivas, emocionais e sociais. Fonterrada (2008), fala da importânciada integração entre a educação infantil, a musicalização, a afetividade e as atividades lúdicas, e de como tal integração favoreceo desenvolvimento das crianças, processo este que a autora chama de educar, aprender, cuidar e brincar.

A educação deve ser um processo envolvente e que desperte interesse e satisfação dos alunos. Assim, como sugere o Referencial Curricular Nacional para a Educação Infantil, o professor pode e deve usar destes recursos (afetividade e lúdico) para promover uma Educação Musical efetiva, em um ambiente de aprendizagem rico e prazeroso para os alunos.

\section{REFERÊNCIAS}

ALMEIDA, A. R. S. A emoção na sala de aula. 5 ed. Campinas: Papirus, 2005.

ANDRADE, A. S. A. A influência da afetividade na aprendizagem, 2007, 43 folhas. Graduação em Psicologia Pedagógica Clínica, Unievangélica Centro Universitário, Brasília. Disponível em: <http://www.arteterapiadf.com.br/textos/monografia completa.pdf>, acesso em: 13 mai. 2012.

BARBOSA, A. M. (org.). Inquietações e Mudanças no Ensino da Arte, 6 ed. São Paulo, Cortez 2011.

BRASIL. Lei n.ㅇ 9.394, de 20 de dezembro de 1996. Estabelece as diretrizes e bases da educação nacional. Diário Oficial da União, Brasília, DF, 20 dez. 1996. Disponível em: <http://legis.senado.leg.br/legislacao/ListaPublicacoes.action?id=102480\&tipoDocumento=LEI\&ti poTexto=PUB>. Acesso em 28 jul. 2013.

. Lei n.o 11.769, de 18 de agosto de 2008. Altera a Lei no 9.394, de 20 de dezembro de 1996, Lei de Diretrizes e Bases da Educação, para dispor sobre a obrigatoriedade do ensino da música na educação básica. Diário Oficial da União, Brasília, DF, 18 ago. 2008. Disponível em: <http://legis.senado.leg.br/legislacao/ListaPublicacoes.action?id=257518\&tipoDocumento=LEl\&ti poTexto=PUB>. Acesso em 28 jul. 2013. 
educação infantil. Brasília: MEC/SEF, 1998. 3v.

Ministério da Educação e do Desporto. Referencial curricular nacional para a BRÉSIA, V. L. P. Educação Musical: bases psicológicas e ação preventiva. São Paulo, Átomo, 2003.

BRITO, T. A. Ferramentas com brinquedos: a caixa da música. Revista da ABEM, Porto Alegre, v. 24, 89-93, set. 2010.

FONTERRADA, M. T. O. De tramas e fios: um ensaio sobre música e educação. 2, ed. São Paulo: Unesp, 2008.

JEANDOT, N. Explorando o universo da música. Série: Pensamento e ação no magistério, ed. São Paulo: Scipione, 1990.

PIAGET, J. Biologia e Conhecimento. Petrópolis: Vozes, 1996.

PINHO, R. O lúdico no processo de aprendizagem. Webartigos, 2009. Disponível em: <http://www.webartigos.com/artigos/o-ludico-no-processo-de-aprendizagem/21258/>. Acesso em 26 mai. 2012.

REZENDE, J. A. Atividades lúdicas relacionadas na terapia da ansiedade para deficientes auditivos. 1993, Monografia, Especialização em Portadores de Necessidades Especiais, Universidade Federal de Uberlândia, Uberlândia. Disponível em: <artigocientifico.uol.com.br/uploads/artc_1299720983_44.doc> acesso em: 20 mai. 2012.

ROSSINI, M. A. S. Aprender tem que ser gostoso. 3a edição, Petrópolis, ed. Vozes, 2003.

SWANWICK, K. Ensinando música musicalmente. ed. São Paulo, Moderna, 2003.

UBALDO, C. O Professor na Educação Infantil. Webartigos, 2009, Disponível em: <http://www.webartigos.com/artigos/o-professor-na-educacao-infantil/14417/>. Acesso em 20 mai. 2012.

VIGOSTSKY, L. S. A formação social da mente. 4ạ ed. São Paulo, Martins Fontes, 1991.

WALLON, H. Psicologia e educação da Infância. ed. Lisboa: Estampa, 1975. 